\title{
Monotongação de ditongos nasais finais átonos em Maceió/AL
}

\section{Monophthongization of final unstressed nasal diphthongs in Maceió/AL}

Ana Maria Santos de Mendonça1, Crislaini da Silva Dias², Alan Jardel de Oliveira ${ }^{3}$

Doutoranda em Linguística pelo Programa de PósGraduação em Letras e Linguistica da Universidade Federal de Alagoas.

E-mail: anamsml@hotmail.com

Mestranda em Linguistica pelo Programa de PósGraduçao em Letra e Linguistica da Un Federal de Alagoas. Bolsista CAPES.

Professor Adjunto da Universidade Federal de Alagoas. Coordenador dos Projetos de Pesquisa - Variação Linguística no português alagoano PORTAL' (CNPq 406218/2012-9) (www.portugues alagoano.com.br) e 'Variação linguística com E-mail: alaniardel@gmail.com
RESUM0: Os ditongos nasais em sílaba átona final são passíveis de redução. Uma palavra como 'jovem' pode ser pronunciada como ['zovẽ̃̃], ['zovĩ], ['3əvi] ou ['zov]. Com base na sociolinguística variacionista, analisa-se o processo de monotongação dos ditongos nasais átonos finais em Maceió/ AL. Para tanto, foram analisados dados de fala espontânea de 36 informantes estratificados por sexo/gênero, faixa etária e escolaridade. Todos os dados foram submetidos à análise acústica. Para a análise estatística, utilizou-se o modelo de regressão multinível, tendo os indivíduos como nível mais agregado. Conclui-se que há interação entre as variáveis sociais sexo/gênero, faixa etária e escolaridade. Entre os homens, a monotongação é diretamente proporcional à idade; entre as mulheres, a faixa etária intermediária realiza mais o processo. Nessa faixa, a escolaridade não é significativa. Nas demais faixas, menos escolarizados monotongam mais. Em relação às variáveis linguísticas, conclui-se que a monotongação é diretamente proporcional ao tamanho da palavra e que o processo é mais frequente no ditongo [ẽ̃]]. 0 processo é inibido em final de enunciados. PALAVRAS-CHAVE: Teoria da Variação e Mudança Linguística; Variação linguística no Português Alagoano; Monotongação de ditongos nasais.

ABSTRACT: Nasal diphthongs in unstressed final syllable are subject to reduction. A word like "jovem" can be pronounced as ['3əvẽ̃ ], ['3əvĩ], ['3əvi] or ['zov]. Based on variationist sociolinguistics, we are analyzing the monophthongization process of final unstressed nasal diphthongs in the city of Maceió / AL. To that aim, spontaneous speech data from 36 participants were analyzed stratified according to gender, age and education. All data were subjected to acoustic analysis. For statistical analysis, we used multilevel regression model, with individuals as more aggregate level. We conclude that there is interaction between social variables such as gender, age and education. Among men, the monophthongization is directly proportional to age; among women, the middle age group performs more the process. In this latter age range, education is not significant. In the other age groups, the less educated, the process is more observed. Regarding linguistic variables, it is concluded that the monophthongization is directly proportional to the size of the word and that the process is more frequent in the diphthong [ẽ̃̃]. The process is inhibited in the final statements.

KEYwords: Theory of Variation and Linguistics Change; Linguistic variation in Portuguese of Alagoas; Monophthongization of nasal diphthongs. 


\section{Introdução}

To português brasileiro (PB), os ditongos nasais em sílaba final átona realizam-se de forma variável. A variante que preserva o ditongo e a nasalidade, como em ['õmẽ̃̃], para 'homem' e['3əẽ̃̃], para jovem, tem como concorrente a forma que reduz o ditongo a um monotongo podendo ou não perder a nasalidade, como ['õmĩ] e ['õmi], ['3əvĩ] e ['3əvi]. Observam-se ainda casos em que a vogal final é apagada, restando apenas a consoante da sílaba final como ['õm] e ['3ov].

Neste estudo, buscamos analisar o processo de monotongação dos ditongos nasais átonos em final de palavra no falar maceioense e investigar os fatores linguísticos e sociais que podem atuar nesse processo. Para tanto, fundamentados na sociolinguística variacionista, analisamos os dados retirados de 36 entrevistas realizadas com falantes da cidade de Maceió/AL. A pesquisa faz parte do projeto 'Variação linguística no português alagoano PORTAL' (aprovado pelo Comitê de Ética da Universidade Federal de Alagoas, CAAE: 24637714.6.0000.5013).

Os dados selecionados foram submetidos a uma análise acústica realizada com o auxílio do software Praat e, em seguida, a uma análise estatística realizada com o auxílio do software R. Consideramos como variável dependente a ocorrência e a não-ocorrência da monotongação em ditongos nasais em sílaba final átona. Como variáveis independentes, consideramos as variáveis sociais 'sexo/gênero', 'faixa etária' e 'escolaridade' e as variáveis linguísticas 'classe da palavra', 'ditongo', 'consoante do onset', 'tonicidade da sílaba seguinte', 'contexto fonológico seguinte' e 'tamanho da palavra'.

\section{Revisão de Literatura}

A monotongação é um processo fonológico no qual ocorre o apagamento da semivogal do ditongo. Esse processo atinge tanto ditongos orais quanto ditongos nasais. Em relação aos ditongos orais decrescentes, segundo Bisol (2012), o processo é favorecido porque esse ditongo possui um glide flutuante, sem representação na estrutura subjacente. Neste contexto, o apagamento da semivogal se dá apenas no nível fonético. Quanto à monotongação dos ditongos nasais, sua ocorrência parece estar relacionada à não reassociação do N extramétrico, fenômeno que ocorre apenas em contexto não acentuado (cf. Bisol, 2013). Para melhor compreendermos a monotongação do ditongo nasal, partiremos dos processos que dão origem a esse tipo de ditongo.

De acordo com Câmara Jr. (1970), o ditongo nasal resulta da sequência 'ditongo mais arquifonema nasal'. Bisol (2013) reinterpreta essa definição à luz da fonologia lexical e afirma que o ditongo nasal pode resultar do processo de estabilidade ou do processo de assimilação. Do primeiro processo, resultam os ditongos lexicais nasais denominados também de verdadeiros ditongos. No processo de estabilidade, a supressão de um segmento não implica o desaparecimento de todos os traços que o compõem. Na formação dos ditongos nasais, o elemento nasal, por não ser articulado, é desassociado da coda silábica, passando a um suprassegmento nasal flutuante, mas que se mantém estável no aguardo de um ambiente favorável à sua reassociação. Após a supressão do elemento nasal, é inserida, na posição de coda silábica, uma vogal temática e o traço nasal é reassociado, percolando toda a rima. Esse processo pode ser visualizado na Figura 1, adiante.

Do processo de assimilação, resultam os ditongos nasais fonéticos (monotongos que sofrem ditongação no nível pós-lexical). Nesse processo, o elemento nasal, ocupante da coda externa, harmoniza-se com a vogal precedente e passa a glide vocálico, como na palavra homem ['õmẽj].

Os ditongos nasais fonéticos, em contextos átonos, no final de palavras, podem não ocorrer. Conforme Bisol (2013), na sequência VN, se a nasal extramétrica não for reassociada, o que emerge é a vogal não nasal, ou seja, um monotongo oral como em ['õmi]. 
Figura 1 - A formação do ditongo nasal na palavra 'pão'

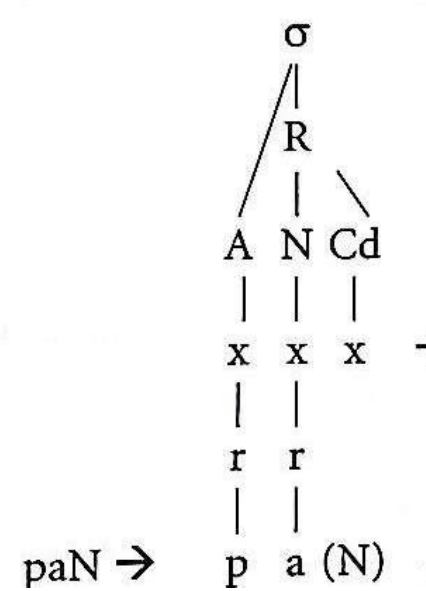

b.

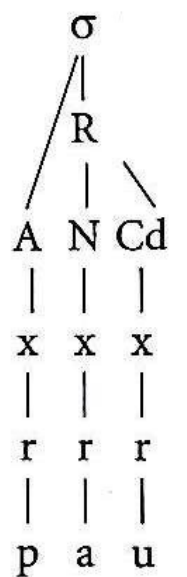

c.

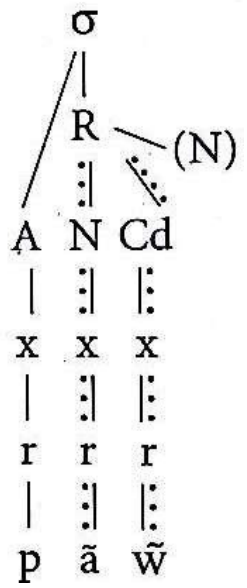

Fonte: Bisol, (2013).

Battisti (2000) e (2002), a partir de dados do Projeto Variação Linguística Urbana na Região Sul do Brasil - VARSUL - investigou a redução dos ditongos nasais átonos no português das capitais da região sul. A amostra analisada foi constituída de 90 entrevistas, sendo 30 do Rio Grande do Sul (RS), 30 de Santa Catarina (SC) e 30 do Paraná (PR). Após rodar as 5.649 ocorrências no VARBRUL, constatou-se que, no nível extralinguístico, a menor escolarização, o sexo masculino, e o estado de Santa Catarina são condicionadores positivos para a aplicação da regra de redução dos ditongos nasais. Em relação às variáveis linguísticas, as classes de palavras (advérbio, nome em -gem e substantivo) e o contexto fonológico seguinte (palavra seguinte iniciada de vogal) favorecem a aplicação da regra de redução do ditongo nasal. Apesar de não ter investigado a variável tonicidade do contexto seguinte, a autora levanta a hipótese de que o contexto seguinte átono é mais favorecedor à redução do ditongo nasal do que o contexto tônico.
Bopp da Silva (2005) analisou a redução da nasalidade em ditongos de sílaba final átona em Porto Alegre e em Panambi. A amostra foi constituída de 24 entrevistas, sendo 12 informantes monolíngues de Porto Alegre e 12 bilíngues de Panambi, comunidade bilíngue português-alemão. Foram analisados 1.728 dados, dos quais $31 \%$ correspondem aos dados de aplicação e $69 \%$ aos dados de não-aplicação da regra. Os resultados apontaram como fatores condicionadores da regra de redução dos ditongos nasais, em ordem de relevância, a) falante monolíngue; b) contexto seguinte ao ditongo; c) posição do onset, da sílaba que contém o ditongo, ocupado por consoante nasal; d) falante com menor número de anos de escolaridade; e) vocábulos terminados em sufixo -gem; f) falante mais jovem; e g) contexto seguinte formado por sílaba átona.

Bopp da Silva e Schwindt (2009) também investigam a redução da nasalidade em ditongos no português falado no sul do Brasil. Esse estudo apresenta como variável dependente os casos em que a nasalidade se perde junto com a redução do ditongo, como por exemplo, órgão $\sim$ órgu. $\mathrm{O}$ trabalho foi desenvolvido a partir de uma amostra de 144 entrevistas que contemplam todas as cidades que compõe o projeto VARSUL. Para análise estatística, foram consideradas as variáveis linguísticas 'classe de palavras', 'consoante do onset', 'tonicidade do contexto seguinte' e 'contexto fonológico seguinte' e as variáveis sociais 'localização geográfica', 'idade', 'escolaridade'.

Nos dados analisados, foram levantados 9.313 contextos de aplicação ou não aplicação da regra investigada. Destes, $34 \%$ correspondem à redução do ditongo nasal. Na pesquisa, a variável social 'localização geográfica' apresentou Santa Catarina como favorecedora e Rio Grande do Sul e Paraná como desfavorecedores, como já apontava Battisti (2000; 2002). Com relação à variável 'classe de palavras', os resultados revelam que a classe dos verbos se mostra inibidora do processo de redução, enquanto que os nomes, sobretudo os com sufixo -gem, favorecem tal processo. A variável 'contexto seguinte', 
quando preenchida por consoante ou pausa, desfavorece a aplicação da redução da nasalidade, enquanto que, quando a vogal ocupa tal contexto, a redução é aplicada. Com relação à variável 'idade', foi observado que o processo é mais aplicado pelos jovens, embora os resultados se aproximem do ponto neutro. Da mesma forma, a variável 'escolaridade', ainda que se aproxime do ponto neutro, aponta que a redução da nasalidade é mais realizada pelos menos escolarizados. Em relação à 'consoante do onset', observou-se que o onset vazio é desfavorecedor do processo, em contraste ao onset preenchido. Em relação à variável tonicidade do 'contexto seguinte', os autores apontam que os contextos tônicos são menos favorecedores da aplicação da redução da nasalidade do que contextos átonos, embora os resultados aproximem-se do ponto neutro.

Outro estudo que analisou quais fatores linguísticos e sociais implicam na redução da nasalidade foi o de Gomes, Mesquita e Fagundes (2013). Esse estudo foi realizado com dados retirados de entrevistas coletadas com 12 informantes do Censo 2000 do Programa de Estudo sobre Uso da Língua (PEUL) - Rio de Janeiro.

A partir dos dados analisados, foram levantados 322 casos de ocorrência da variação. Destes, $45 \%$ correspondem à aplicação da vogal oral. Para o estudo, foram consideradas as variáveis sociais 'escolaridade' e 'sexo', as variáveis linguísticas 'contexto seguinte', 'vogal núcleo do ditongo', 'distância da sílaba tônica seguinte', 'tamanho do item lexical', 'status morfológico' e as variáveis aleatórias 'item lexical' e 'indivíduo'. Das variáveis apresentadas, segundo os autores, o programa selecionou a variável aleatória 'item lexical', e as variáveis independentes, na seguinte ordem, 'escolaridade' ( $p .=0.00103)$, 'idade' ( $\mathrm{p}=0.00345)$ e 'distância da sílaba tônica seguinte' ( $\mathrm{p}=0.0354)$ como sendo significantes para a aplicação da vogal oral.

A análise revelou que há uma tendência de uso da variante oral por parte dos menos escolarizados. Além disso, foi observado que quanto maior a distância da sílaba seguinte, maior a probabilidade de ocorrência da variante oral. Ainda, pode-se verificar que há variação estável, uma vez que não existe diferença de uso da variante oral pelos mais velhos e mais jovens. Constatou-se também quea alternância do ditongo nasal com a vogal oral pode estar relacionada à posição fraca do ditongo em sílaba átona final, o que possibilita o espraiamento da variante oral reduzida. Por fim, foi verificado que o processo de redução da nasalidade tem frequência diferente em função do item lexical.

\section{Metodologia}

Este trabalho fundamenta-se nos pressupostos teórico-metodológicos desenvolvidos pela sociolinguística variacionista, conforme apresentados por Weinreich, Labov e Herzog (1968) e Labov (1972). Uma análise baseada em aspectos teórico-metodológicos variacionistas permite identificar a relação entre a produção de uma variante associada probabilisticamente a algum fator linguístico ou social. Nesta perspectiva, a variação é, a priori, um processo motivado por um conjunto de fatores identificáveis e mensuráveis estatisticamente e, portanto, não é aleatória.

De acordo com o Labov (1972), interessa à sociolinguística, principalmente, a análise de estilos nos quais "encontramos a fala mais sistemática, onde as relações fundamentais que determinam o curso da evolução linguística podem ser vistas mais claramente" (LABOV, 2008 [1972], p. 244). Tal estilo é chamado de vernáculo e é o estilo "em que se presta o mínimo de atenção ao monitoramento da fala" (LABOV, 2008 [1972], p. 244).

Labov afirma ainda que em uma entrevista não se deve esperar encontrar o vernáculo em uso, já que, nessa situação a fala é sempre mais monitorada do que nas situações mais informais. Diante disso, Labov chega ao que chamou de paradoxo do observador, assim apresentado pelo autor: 
O objetivo da pesquisa linguística na comunidade deve ser descobrir como as pessoas falam quando não estão sendo sistematicamente observadas - no entanto, só podemos obter tais dados por meio da observação sistemática (LABOV, 1972, p. 244).

Labov propõe que o paradoxo pode ser superado com certas estratégias que rompam os constrangimentos da situação de entrevista. Uma das propostas do autor é que os informantes sejam envolvidos com perguntas e assuntos que lhes recriem emoções fortes do passado.

Em nossa pesquisa, os dados foram extraídos de gravações de narrativas espontâneas, já que esse gênero recebe menos monitoramento por parte dos falantes. As gravações tiveram duração de 9 a 11 minutos e foram realizadas com 36 informantes, nascidos em Maceió ou residentes nessa cidade há mais de 20 anos. A amostra foi segmentada de acordo com o Quadro 1.

Quadro 1 - Células sociais

\begin{tabular}{|c|c|c|c|}
\hline Sexo/Gênero & Faixa Etária & Escolaridade & № de Participantes \\
\hline \multirow{6}{*}{ Feminino } & \multirow{2}{*}{ Entre 18 e 35 anos } & $<9$ anos & 3 \\
\hline & & $>11$ anos & 3 \\
\hline & \multirow{2}{*}{ De 36 a 55 anos } & $<9$ anos & 3 \\
\hline & & $>11$ anos & 3 \\
\hline & \multirow{2}{*}{ Acima de 55 anos } & $<9$ anos & 3 \\
\hline & & $>11$ anos & 3 \\
\hline \multirow{6}{*}{ Masculino } & \multirow{2}{*}{ Entre 18 e 35 anos } & $<9$ anos & 3 \\
\hline & & $>11$ anos & 3 \\
\hline & \multirow{2}{*}{ De 36 a 55 anos } & $<9$ anos & 3 \\
\hline & & $>11$ anos & 3 \\
\hline & \multirow{2}{*}{ Acima de 55 anos } & $<9$ anos & 3 \\
\hline & & $>11$ anos & 3 \\
\hline \multicolumn{3}{|c|}{ Total de Participantes } & 36 \\
\hline
\end{tabular}

Scherre e Yacovenco (2011) apresentam uma discussão sobre o paradoxo do gênero levantado por Labov (2001), por meio da análise da alternância entre tu e você a partir de dados das cinco regiões brasileiras.
Após a análise dos resultados, as autoras propõem duas generalizações: "em configurações menos marcadas - e não necessariamente mais prestigiadas as mulheres estão à frente na variação ou na mudança" e "em configurações mais marcadas - e não necessariamente menos prestigiadas - os homens estão à frente na variação ou na mudança" (SCHERRE e YACOVENCO, 2011, p. 139). As autoras sugerem uma agenda de trabalho para investigação da relação entre variação linguística e o gênero. Neste trabalho, adotaremos a terminologia 'sexo/gênero', utilizada em muitos trabalhos variacionistas e defendida por Freitag (2015, p. 29), trabalho no qual a autora discute e problematiza tal variável em estudos variacionistas.

Interessa-nos investigar, por meio da análise da variável 'faixa etária', se a monotongação pode ser classificada como um caso de variação estável, de mudança incipiente ou de mudança em progresso. A análise sincrônica da variação linguística permite tal análise com base na hipótese do tempo aparente (LABOV, 1972).Interessa-nos investigartambém se o processo é influenciado pela escolaridade. A hipótese é que o aumento na exposição do falante à norma culta, propiciado pela escola, possa influenciar na produção de variantes avaliadas socialmente. A tendência é que variantes socialmente estigmatizadas sejam menos produzidas por aqueles que tiveram mais acesso à norma culta. Para evitarmos o aumento da amostra e evidenciarmos o efeito da escolaridade no processo, optamos por analisar somente dois grupos: aqueles que têm até o ensino fundamental ( $<9$ anos de escolaridade) e aqueles que têm escolaridade acima de ensino médio ( $>11$ de escolaridade).

A entrevista foi guiada por perguntas que fizeram os informantes relatarem sobre a sua infância e adolescência na cidade; a descrever sua casa e a cidade nesses períodos e a se posicionarem sobre os temas polêmicos como aborto, casamento homossexual e pena de morte.

As gravações foram transcritas utilizando o Software Praat. As ocorrências foram identificadas de forma automática utilizando-se rotinas de 
busca do software Microsoft Word e o banco de dados, contendo as variáveis analisadas no estudo, foi criado no software Microsoft Excel.

No Quadro 2, a seguir, apresentamos a distribuição das variáveis linguísticas consideradas no estudo, fundamentadas, principalmente, com base em outros estudos realizados sobre o tema no PB, como Votre (1978), Battisti (2000) e (2002), Bopp da Silva (2005), Bopp da Silva e Schwindt (2009) e Gomes, Mesquitae Fagundes (2013).

Quadro 2 - Distribuição das variáveis linguísticas

\begin{tabular}{|c|c|}
\hline Grupo de Fatores & Exemplos \\
\hline $\begin{array}{l}\text { Classe de Palavras } \\
\text { Substantivo } \\
\text { Verbo }\end{array}$ & $\begin{array}{l}\text { órgão } \\
\text { começaram }\end{array}$ \\
\hline $\begin{array}{l}\text { Ditongo } \\
\text { [ã } \tilde{]}] \\
\text { [ẽ̃̃] }\end{array}$ & $\begin{array}{l}\text { fizeram } \\
\text { imagem }\end{array}$ \\
\hline $\begin{array}{l}\text { Consoante do onset } \\
{[\mathrm{p}, \mathrm{b}]} \\
{[\mathrm{t}, \mathrm{d}]} \\
{[\mathrm{k}, \mathrm{g}]} \\
{[\mathrm{f}, \mathrm{v}]} \\
{[\mathrm{s}, \mathrm{z}]} \\
{[\mathrm{f}, 3]} \\
{[\mathrm{m}]} \\
{[\mathrm{n}]} \\
{[\mathrm{h}]} \\
{[\mathrm{r}]} \\
{[\kappa]} \\
{[\mathrm{n}]} \\
{[\mathrm{l}]} \\
\text { onset vazio } \\
\end{array}$ & $\begin{array}{l}\text { acabem } \\
\text { aceitam } \\
\text { órgão } \\
\text { gostaamam } \\
\text { dizem } \\
\text { garagem } \\
\text { homem } \\
\text { acenam } \\
\text { corram } \\
\text { compraram } \\
\text { falham } \\
\text { tịhham } \\
\text { falam } \\
\text { queriam }\end{array}$ \\
\hline $\begin{array}{l}\text { Tonicidade da sílaba seguinte } \\
\text { Átono } \\
\text { Tônico }\end{array}$ & $\begin{array}{l}\text { eram meninas } \\
\text { eram muito }\end{array}$ \\
\hline $\begin{array}{l}\text { Contexto Fonológico Seguinte } \\
\text { Vogal } \\
\text { Pausa } \\
\text { Consoante } \\
\end{array}$ & $\begin{array}{l}\text { eram amigas } \\
\text { garagem } \\
\text { falam muito }\end{array}$ \\
\hline $\begin{array}{l}\text { Tamanho da palavra } \\
\text { variável contínua medida pela quantidade de } \\
\text { sílabas }\end{array}$ & $\begin{array}{l}\text { jovem(2), feriram(3), enfermagem(4), } \\
\text { abandonaram(5) }\end{array}$ \\
\hline
\end{tabular}

\subsection{Identificação acústica das variantes}

Todos os dados desta pesquisa foram submetidos à análise acústica com o objetivo de buscarmos, de maneira mais confiável, pistas que nos levaram a identificar a ausência da semivogal, o que indica a monotongação. No espectrograma, observamos o comportamento do primeiro e do segundo formantes (zonas de frequência em que há maior concentração de energia acústica, presentes de forma mais evidente nas vogais, semivogais, consoantes nasais e consoantes laterais). A zona de frequência mais grave é chamada de primeiro formante (F1) e a zona de frequência imediatamente superior é chamada de segundo formante (F2).

De acordo com Demasi (2009), no ditongo nasal anterior (como em 'jovem' e 'homem'), percebe-se a elevação de F2 na passagem da vogal para o glide. No ditongo nasal posterior (como em 'órgão' e 'falaram'), percebe-se o abaixamento de F2 na passagem da vogal para o glide. Esses foram os correlatos acústicos utilizados neste trabalho para classificar a ocorrência como manutenção do ditongo ou monotongação, conforme pode-se observar nos exemplos a seguir, Figuras 2 e 3.

Figura 2 - Espectrograma da palavra "homem"

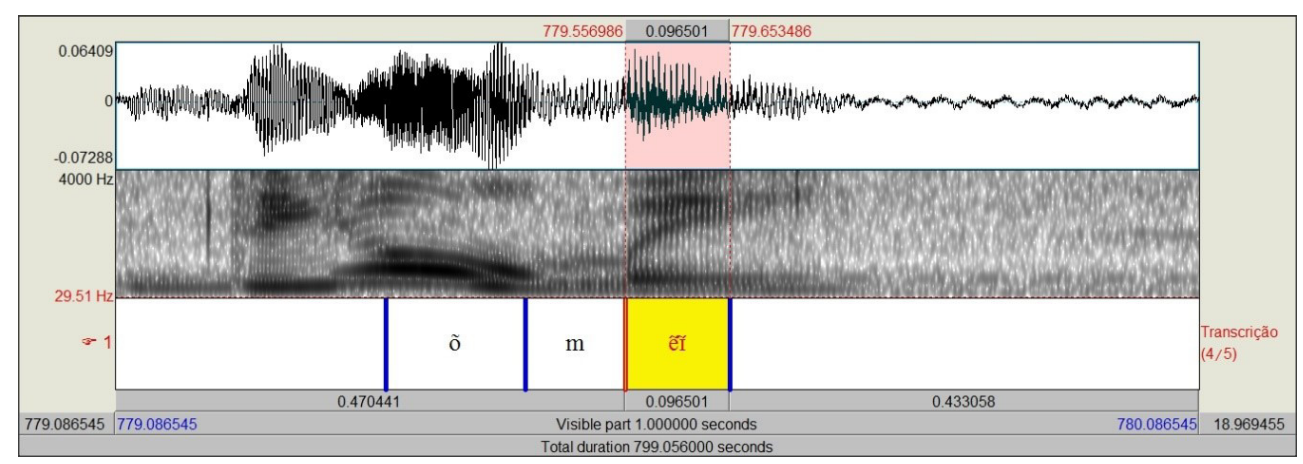


Figura 3 - Espectrograma da palavra "separaram"

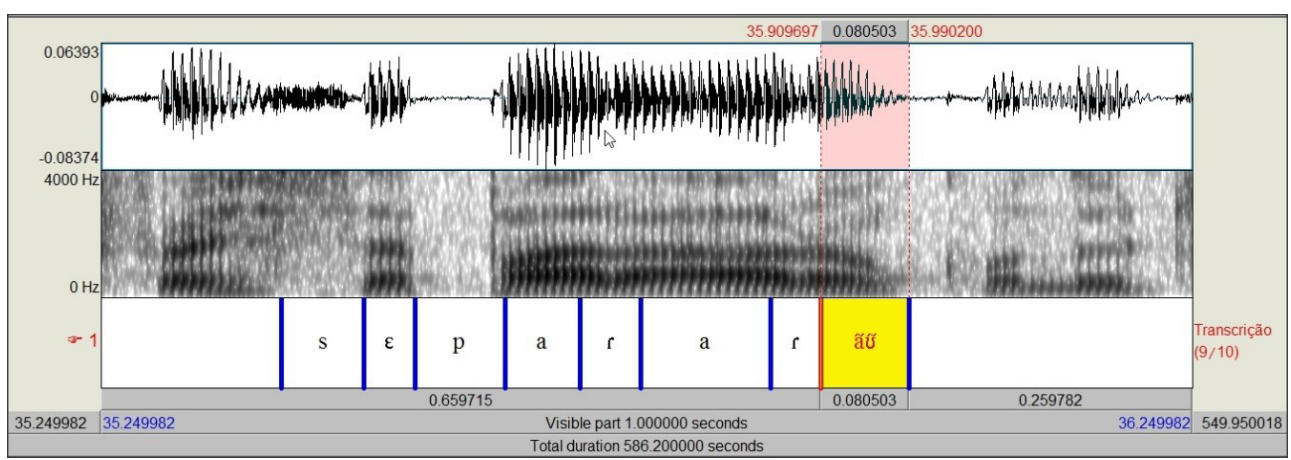

A elevação de F2 na Fig. 2 indica que houve transição da vogal [ẽ] para a semivogal [ĩ]. Do mesmo modo, o abaixamento de F2 na Fig. 3 indica que houve transição da vogal [ã] para a vogal [̛̃]. Em nossas análises, alterações em F2 foram classificadas como manutenção do ditongo final. Diferentemente, quando não houve alteração em F2, as ocorrências foram classificadas como monotongação, como ilustrado nas Figuras 4 e 5 a seguir.

Figura 4 - Espectrograma da palavra "jovem"

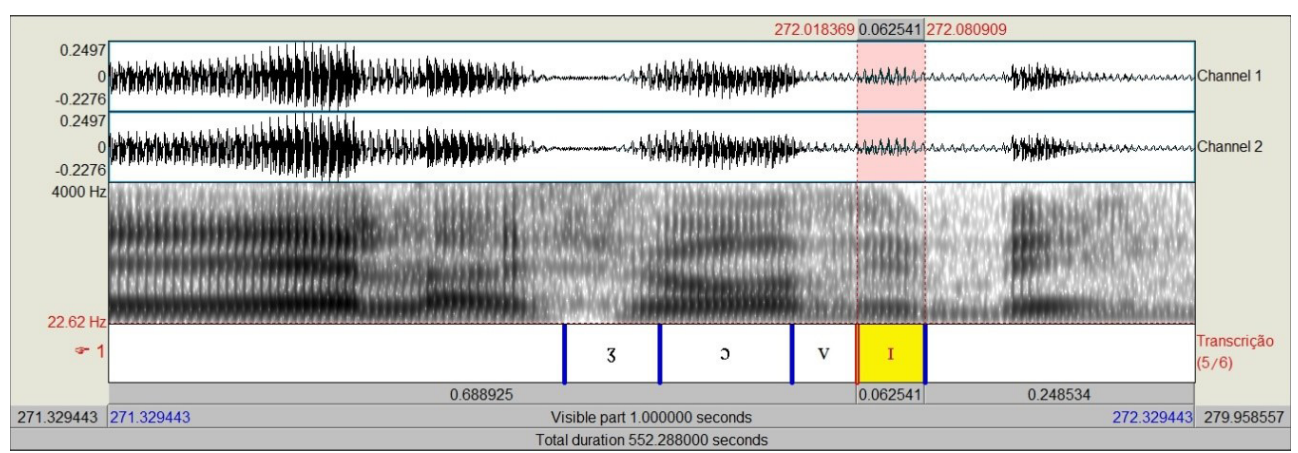

Figura 5 - Espectrograma da palavra "foram"

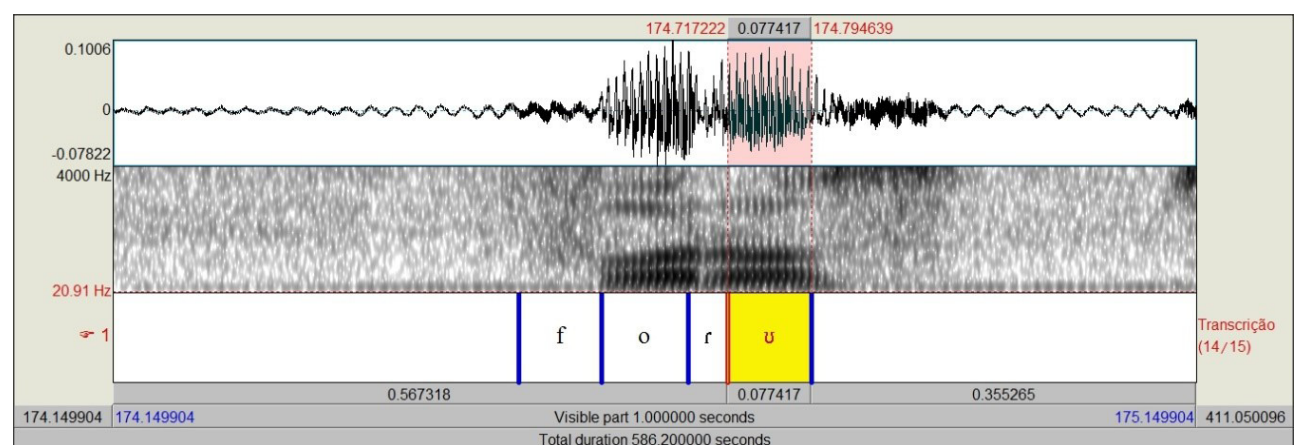

Nas Figuras 4 e 5, não se pode observar elevação ou redução em F2 no momento da produção do ditongo, o que indica que houve a produção de somente uma vogal, caracterizando o processo que estamos investigando neste trabalho, a monotongação.

\subsection{Metodologia da análise estatística}

Na análise quantitativa, foram utilizados métodos inferenciais de análise estatística (tabelas de contingência, testes univariados e multivariados e métodos de regressão multinível). A seleção das variáveis estatisticamente significativas foi feitaseguindo os critérios apresentados Hosmer e Lemeshow (2001).

A estimação dos efeitos associados às variáveis independentes foi feita com o uso de modelos de regressão logística multinível. Os dados analisados neste trabalho possuem estrutura hierárquica já que as observações podem ser agrupadas segundo os indivíduos que as produziram. De acordo com Johnson (2008), os modelos de regressão multinível são mais adequados para dados que possuem estrutura hierárquica porque incorporam naturalmente essa estrutura na regressão. 
A análise estatística foi feita com o auxílio do software R, utilizando os pacotes 'gmodels' (para tabelas de contingência e teste qui-quadrado), 'Ime4' (para regressão logística multinível), 'multicomp' (para o teste de Tukey, que calcula a significância entre os efeitos dosfatores em variáveis independentes). Os pesos relativos foram calculados alterando-se o contraste entre as variáveis independentes. Ao invés de tomar um dos fatores como referência (padrão na maioria dos softwares estatísticos), essa alteração permite que a categoria de referência seja a média entre os efeitos dos fatores (método desvio da média) (OLIVEIRA, 2009). Descrições mais detalhadas dos procedimentos podem ser encontradas em www.valr.com.br (Projeto VaLR).

\section{Resultados}

Neste estudo, foram identificados 326 contextos propícios à realização da monotongação em ditongos nasais finais átonos, dos quais 204 foram monotongados e 122 realizaram-se como ditongos, como podemos observar na Tabela 1.

Tabela 1 - Variação em ditongos nasais finais átonos em Maceió/AL

\begin{tabular}{lcc}
\hline Variantes & Total & $\%$ \\
Ditongo & 122 & 38,4 \\
Monotongação & 204 & 62,6 \\
Total & 326 & 100,0 \\
\hline
\end{tabular}

Em Maceió/AL, a monotongação de ditongos nasais finais átonos é mais frequente $(62,6 \%)$ do que em outros locais do Brasil, como mostram os estudos de Battisti (2000 e 2002) (43\%), Bopp da Silva (2005) (31\%), Schwindt eBopp da Silva (2009) (34\%), sobre falares da região Sul; e de Gomes, Mesquita e Fagundes (2013) (45\%), sobre o falar do Rio de Janeiro.
A frequência mais alta em Maceió pode ser evidência de um processo mais avançado nessa variedade, mas pode também ser decorrente do método de identificação de variantes. Neste trabalho, tal identificação se deu por correlatos acústicos da presença ou ausência do glide em análise espectrográfica.

$\mathrm{Na}$ análise inicial dos dados, foram criadas tabelas de contingência e realizados testes de significância estatística (qui-quadrado) para cada uma das variáveis independentes. Nesta etapa, as variáveis 'sexo/gênero', 'tamanho da palavra', 'classe de palavras', ditongo'e 'consoante do onset'apresentaram p-valor maior que 0,05 no teste qui-quadrado, o que significa que a diferença observada entre os fatores não é estatisticamente significativa. As variáveis 'faixa etária', 'escolaridade', 'tonicidade da sílaba seguinte' e 'contexto fonológico seguinte’ apresentaram significância estatística.

Rodando o modelo de regressão logística multinível incluindo todas as variáveis simultaneamente (modelo multivariado) e incluindo o indivíduo como nível mais agregado, constatamos que as variáveis linguísticas 'tamanho da palavra', 'contexto seguinte', 'consoante do onset' e 'ditongo' apresentaram significância estatística. As variáveis linguísticas 'classe da palavra' e 'tonicidade seguinte’ não foram consideradas estatisticamente significativas.

Com relação às variáveis sociais, analisadas isoladamente, somente a variável 'escolaridade' mostrou-se como estatisticamente significativa, apontando que a monotongação é favorecida entre os menos escolarizados. Após investigarmos a interação entre variáveis sociais, constatamos que a variável 'escolaridade' interage com as variáveis 'sexo/gênero' e 'faixa etária'. Incluindo os termos de interação no modelo final, todas as variáveis sociais investigadas apresentaram significância estatística.

O modelo final, portanto, inclui a interação entre as variáveis sociais 'escolaridade', 'sexo/gênero' e 'faixa etária', e as variáveis linguísticas 'tamanho da palavra', contexto seguinte, consoante do onset e ditongo. 
Nas tabelas a seguir, a coluna sig. representa o $p$-valor do teste de Wald, cuja hipótese nula afirma que não há diferença entre o fator de referência e o fator testado. Neste trabalho, o fator de referência é a média dos fatores. Assim, se sig. $<0,05$, conclui-se que a hipótese nula pode ser negada e que, portanto, o efeito do fator difere-se do efeito médio (ou do ponto neutro cujo peso relativo $=0,50$ ).

Vejamos com mais detalhes a análise dos condicionadores da monotongação em ditongos nasais átonos.

\subsection{Variáveis sociais}

Ao testarmos a interação entre variáveis sociais, constatamos que a interação entre a variável 'escolaridade' e as variáveis 'faixa etária' e 'escolaridade' é estatisticamente significativa e que, portanto, tais variáveis devem ser analisadas conjuntamente. Diante disso, no modelo final de regressão, foi inserido o termo de interação entre as variáveis sociais. $\mathrm{Na}$ prática, foi criada uma única variável pela multiplicação das variáveis 'sexo/ gênero', ‘escolaridade' e 'faixa etária'. Vejamos os resultados dessa variável:

Tabela 2 - Monotongação de ditongos nasais finais átonos em relação às variáveis sociais

\begin{tabular}{|c|c|c|c|c|c|c|}
\hline Sexo/Gênero & Escolaridade & Faixa Etária & Total & $\%$ & Peso Relativo & Sig. \\
\hline \multirow{6}{*}{ Feminino } & \multirow{3}{*}{$\leq 9$ anos } & 18 a 35 anos & 18 & 55,6 & 0,36 & 0,254 \\
\hline & & 36 a 55 anos & 16 & 93,8 & 0,85 & 0,083 \\
\hline & & + de 56 anos & 10 & 90,0 & 0,87 & 0,070 \\
\hline & \multirow{3}{*}{$\geq 11$ anos } & 18 a 35 anos & 21 & 52,4 & 0,22 & 0,006 \\
\hline & & 36 a 55 anos & 19 & 73,7 & 0,53 & 0,849 \\
\hline & & + de 56 anos & 35 & 51,4 & 0,23 & 0,004 \\
\hline \multirow{6}{*}{ Masculino } & \multirow{3}{*}{$\leq 9$ anos } & 18 a 35 anos & 15 & 73,3 & 0,65 & 0,350 \\
\hline & & 36 a 55 anos & 24 & 54,2 & 0,28 & 0,040 \\
\hline & & + de 56 anos & 24 & 95,8 & 0,88 & 0,039 \\
\hline & \multirow{3}{*}{$\geq 11$ anos } & 18 a 35 anos & 53 & 45,3 & 0,26 & 0,002 \\
\hline & & 36 a 55 anos & 27 & 63,0 & 0,39 & 0,340 \\
\hline & & + de 56 anos & 64 & 60,9 & 0,30 & 0,010 \\
\hline Total & & & 326 & 62,6 & & \\
\hline
\end{tabular}

Gráfico 1 - Interação entre sexo/gênero, faixa etária e escolaridade na monotongação de ditongos nasais finais átonos

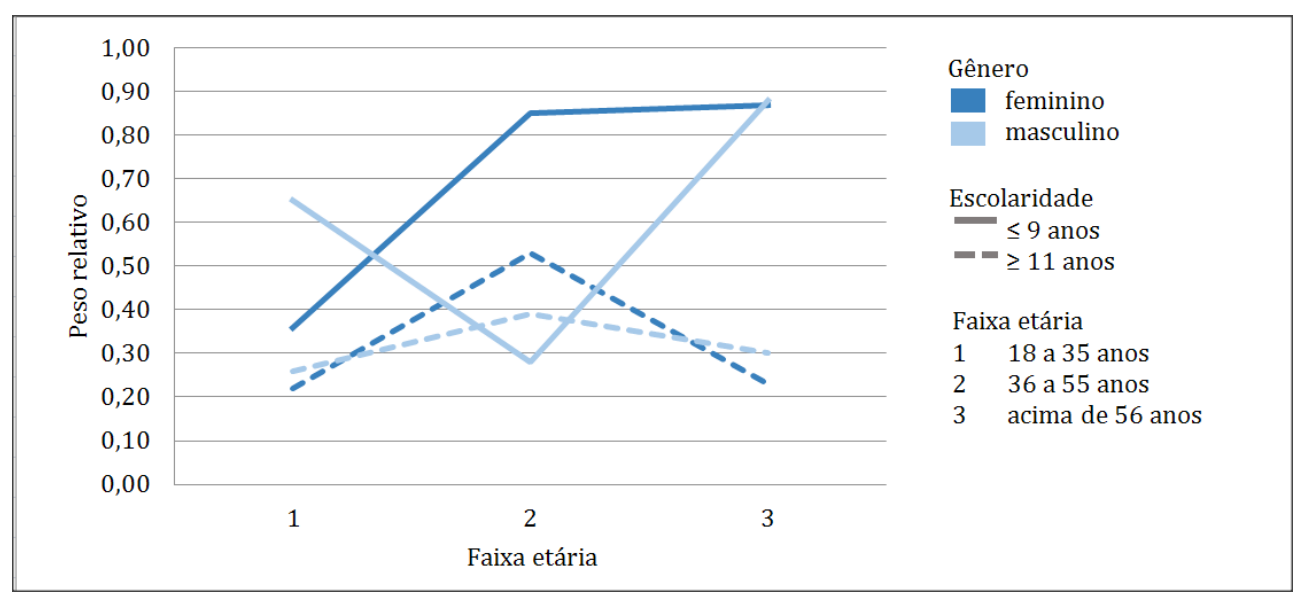

No feminino, observamos que falantes de escolaridade mais baixa favorecem a monotongação. Entre os menos escolarizados, a monotongação é diretamente proporcional à idade. Entre os mais escolarizados, a faixa etária intermediária realiza mais o processo.

No masculino, os níveis de escolaridade apresentam resultados inversos para as faixas etárias. Entre os menos escolarizados, há um favorecimento das faixas 1 e 3; entre os mais escolarizados, a faixa 2 favorece o processo.

Entre os falantes mais escolarizados, a diferença entre feminino e masculino é minimizada. A faixa etária intermediária favorece o processo em ambos os sexos/gêneros e as faixas das extremidades apresentam pesos relativos semelhantes.

Entre os menos escolarizados, há um favorecimento da monotongação entre os mais velhos. Nas demais faixa etárias, há uma inversão: entre os mais jovens, masculino tem $P R=0,65$ e feminino tem $P R=0,36$. Na faixa intermediária, masculino tem $\mathrm{PR}=0,28$ e feminino tem $\mathrm{PR}=0,85$. 
Battisti (2000 e 2002); Bopp da Silva (2005); Bopp da Silva e Schwindt (2009) e Gomes, Mesquita e Fagundes (2013) mostraram que, nas regiões pesquisadas, o aumento da escolaridade tem efeito na redução da monotongação. De um modo geral, neste trabalho, também parece haver uma tendência de diminuição da monotongação com o aumento da escolaridade.Na escolaridade mais alta, a diferença entre feminino e masculino e as idades é minimizada. Na escolaridade mais baixa, entretanto, o resultado parece ser mais caótico, motivado, principalmente, pelos homens de faixa etária intermediária. Não há indícios de um processo de mudança linguística em progresso.

Estudos futuros, com ampliação da amostra, poderão tornar mais clara a interferência dos fatores sociais na monotongação de ditongos nasais finais átonos em Maceió/AL.

\subsection{Variáveis linguísticas}

As variáveis linguísticas que apresentaram significância estatística no processo analisado neste trabalho foram 'contexto seguinte', 'tamanho da palavra', 'ditongo' e 'consoante do onset' (substituída pela variável 'traço [ \pm estridente] da consoante do onset'].

A Tabela 3 a seguir apresenta o resultado para a variável 'contexto seguinte'.

Tabela 3 - Monotongação de ditongos nasais finais átonos em relação ao contexto seguinte

\begin{tabular}{lcccc}
\hline Contexto seguinte & Total & $\%$ & Peso Relativo & Sig. \\
consoante & 183 & 67,2 & 0,66 & $<0,001$ \\
vogal & 97 & 69,1 & 0,67 & 0,001 \\
pausa & 46 & 30,4 & 0,20 & $<0,001$ \\
Total & 326 & 62,6 & & \\
\hline
\end{tabular}

Os resultados apresentados na Tabela 3 nos indicam que o processo é influenciado pela ausência de contexto fonético seguinte. A diferença entre consoante e vogal é muito pequena e não é estatisticamente significativa (no teste de Tukey, a significância entre tais fatores é de 0,984 ).

Em estudos realizados sobre o português do sul do Brasil (BATTISTI, 2000 e 2002; BOPP DA SILVA. 2005; BOPP DA SILVA e SCHWINDT, 2009), observou-se que, além da pausa, o contexto seguinte 'consoante' também desfavorece o processo. A monotongação seria favorecida pela presença de vogal seguinte.

Vejamos a seguir os resultados para a variável 'tamanho da palavra'.

Gráfico 2 - Monotongação de ditongos nasais finais átonos em relação ao 'tamanho da palavra'

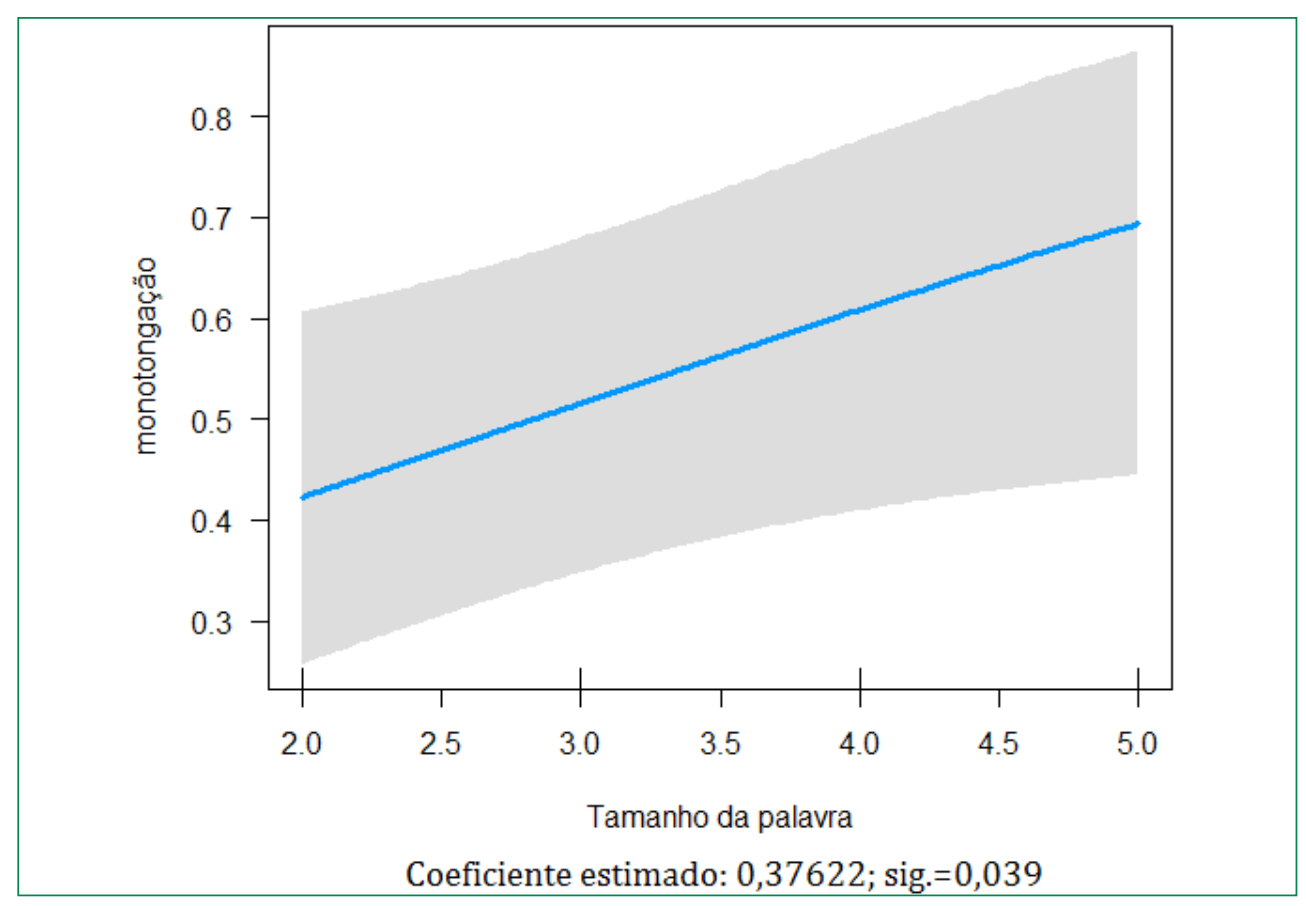


Observando o Gráfico 2, identificamos uma relação diretamente proporcional entre a monotongação e o tamanho da palavra; quanto maior a palavra, maior a probabilidade de monotongação. Analisando a redução da nasalidade em ditongos finais átonos, Votre (1978), apud Battisti (2002), afirma que "os vocábulos polissílabos devem ter sido os primeiros atingidos pela tendência à simplificação da estrutura silábica, seguidos pelos dissílabos e monossílabos, que são os mais resistentes à mudança" (VOTRE, 1978, p. 188).

Neste trabalho, o objeto de estudo é a monotongação, não a desnasalização, como em Votre (1978). Nas análises acústicas, identificamos as variantes ditongo nasal, monotongo nasal, monotongo oral e apagamento do ditongo. A variante ditongo oral não foi observada. Sendo assim, parece que a monotongação ocorre antes da desnasalização. A hipótese de Votre (1978) poderia ser aplicada a este estudo, tanto em relação à monotongação quanto à perda da nasalização, já que ambos os processos envolvem simplificação da estrutura silábica.

Vejamos os resultados para a variável 'consoante do onset':

Tabela 4 - Monotongação de ditongos nasais finais átonos em relação à 'consoante do onset'

\begin{tabular}{lcccc}
\hline Consoante do onset & Total & \% & PR & Sig. \\
{$[\mathrm{s}, \mathrm{z}]$} & 12 & 91,7 & 0,90 & 0,043 \\
{$[\mathrm{~s}, 3]$} & 30 & 76,7 & 0,63 & 0,332 \\
{$[\mathrm{f}, \mathrm{v}]$} & 50 & 64,0 & 0,59 & 0,367 \\
{$[\mathrm{~m}]$} & 62 & 64,5 & 0,49 & 0,921 \\
{$[\mathrm{k}, \mathrm{g}]$} & 6 & 50,0 & 0,45 & 0,826 \\
{$[\mathrm{r}]$} & 133 & 60,9 & 0,45 & 0,545 \\
{$[\mathrm{n}]$} & 7 & 42,9 & 0,39 & 0,595 \\
{$[\mathrm{t}, \mathrm{d}]$} & 14 & 57,1 & 0,39 & 0,432 \\
onset vazio & 12 & 25,0 & 0,15 & 0,012 \\
Total & 326 & 62,6 & & \\
\hline
\end{tabular}

Analisando os dados da Tabela 4, observamos que os únicos fatores estatisticamente significativos são $[s, z]$ e onset vazio. Considerando os pesos relativos, vemos que, além de [s,z], as consoantes [ $[\mathrm{s}, 3]$ e [f,v] foram as únicas acima de 0,50. Diante disso, podemos sugerir que a monotongação pode estar associada ao traço [+estridente] da consoante do onset. Para testar essa hipótese, uma nova variável binária traço [ \pm estridente] da consoante do onset foi criada. A fim de verificar qual das variáveis é mais explicativa, realizamos um teste de significância entre os dois modelos (teste da razão da máxima verossimilhança), um modelo incluindo a variável 'consoante do onset' (com 9 fatores) e outro incluindo a variável 'traço [ \pm estridente] da consoante do onset' (com 2 fatores). 0 resultado do teste foi sig. $=0,305$, o que indica que a hipótese nula que afirma que ambos os modelos são iguais não pode ser negada e que, portanto, os modelos não são significativamente diferentes. Por esse motivo, devemos optar pelo modelo mais simples, ou seja, aquele que inclui a variável 'traço [ \pm estridente] da consoante do onset'. Vejamos a seguir o resultado desta variável.

Tabela 5 - Monotongação de ditongos nasais finais átonos em relação ao 'traço [ \pm estridente] da consoante do onset'

\begin{tabular}{|c|c|c|c|c|}
\hline $\begin{array}{l}\text { Traço [ } \pm \text { estridente] } \\
\text { da consoante do onset }\end{array}$ & Total & $\%$ & Peso Relativo & Sig. \\
\hline [+estridente] & 92 & 71,7 & 0,60 & 0,012 \\
\hline [-estridente] & 234 & 59,0 & 0,40 & 0,012 \\
\hline Total & 326 & 62,6 & & \\
\hline
\end{tabular}

Como podemos observar na Tabela 5, a monotongação é favorecida quando a consoante do onset apresenta o traço [+estridente]. Diferentemente de outros estudos, nossos resultados apontaram que a variável 'classe da palavra' não se mostrou estatisticamente significativa para a realização da monotongação. Em Battisti $(2000,2002)$, Bopp da Silva (2005) e Bopp da 
Silva e Schwindt (2009), a variável 'classe da palavra' continha um fator 'nomes com -gem', o qual incluía substantivos terminados em -gem, como 'origem', 'garagem', etc. Ao invés de incluir esse fator, optamos por investigar a consoante do onset a fim de verificar se o favorecimento do morfema -gem não estaria relacionado a algum critério fonético-fonológico, e não morfológico ou lexical. Temos indícios de que o processo de monotongação não está sujeito a condicionadores morfológicos e/ou lexicais. Esses indícios precisam ser investigados com mais profundidade, a partir de um banco de dados mais amplo e com maior diversidade de palavras. Por enquanto, podemos afirmar que o traço [+estridente] favorece a monotongação.

Vejamos os resultados para a variável 'ditongo'.

Tabela 6 - Monotongação de ditongos nasais finais átonos em relação ao 'ditongo'

\begin{tabular}{lcccc}
\hline Ditongo & Total & $\%$ & Peso Relativo & Sig. \\
[ã̃̃] & 180 & 60,6 & 0,41 & 0,020 \\
[ẽ̃̃ & 146 & 65,1 & 0,59 & 0,020 \\
Total & 326 & 62,6 & & \\
\hline
\end{tabular}

Os resultados apresentados na Tabela 6 indicam que a monotongação é favorecida no ditongo [ẽ̃̃] em relação ao ditongo [ãõ]. Oliveira (2012), analisando dados de Itaúna/MG, mostra que há um processo bastante frequente de enfraquecimento da vogal átona final que, na maior parte das vezes, resulta no apagamento completo da vogal final em sílabas CV. Nesse estudo, os resultados mostram que a redução tem motivação fonética, visto que as vogais mais altas, tanto a anterior, quanto a posterior, apresentam apagamento muito superior à vogal baixa final. Acreditamos que o favorecimento da monotongação do ditongo [ẽ̃̃] possa ter motivação fonética e atingir mais frequentemente a vogal [e] do que a vogal [a].

\section{Conclusão}

Esse trabalho apresentou uma análise variacionista da monotongação de ditongos nasais finais átonos no falar maceioense. A identificação das variantes do processo foi feita a partir da análise acústica das ocorrências. Foram identificadas, além do ditongo, a monotongação, a desnasalização e o apagamento da vogal. O processo foi analisado como uma variável binária, contrapondo o ditongo às demais variantes, visto que a desnasalização e o apagamento da vogal são processos posteriores à monotongação.

Em relação às variáveis sociais, identificamos que há interação entre sexo/gênero, faixa etária e escolaridade. Há indícios de que o aumento da escolaridade desfavoreça a monotongação, resultado observado em outros estudos como Battisti (2000; 2002), Bopp da Silva (2005), Bopp da Silva e Schwindt (2009) e Gomes, Mesquita e Fagundes (2013). Outros estudos precisam ser realizados a fim de se entender melhor a interferência de fatores sociais no processo.

Em relação aos fatores linguísticos, concluímos que a monotongação é desfavorecida na ausência de segmento seguinte. Diferentemente de outros estudos, em Maceió/AL, o contexto seguinte consonantal favorece tanto o processo quanto o contexto vocálico. Concluímos que a monotongação é diretamente proporcional ao tamanho da palavra, o que poderia estar relacionado à hipótese de Votre (1978) de que simplificação da estrutura silábica nos ditongos nasais finais atinge primeiramente vocábulos maiores. Em relação à consoante do onset, concluímos que a monotongação está relacionada à presença do traço [+estridente] na consoante do onset. Esse resultado podeajudar a explicar ofavorecimento dos nomes com-gem em outros estudos. Por fim, concluímos que o ditongo [ẽ̃̃] favorece a monotongação em comparação ao ditongo [ã̃u]. Acreditamos que o apagamento da vogal 
tem motivação fonética, ocorrendo mais frequentemente em vogais mais reduzidas foneticamente.

Esse estudo apresentou uma faceta ainda não investigada sobre o falar alagoano. Estudos futuros poderão ajudar a elucidar a interferência das variáveis sociais no processo e a entender melhor a interferência dos condicionadores linguísticos.

\section{Referências}

BATTISTI, Elisa. A redução variável dos ditongos nasais átonos no português do sul do Brasil. Letras de hoje, n. 35, mar; 2000.

BATTISTI, Elisa. A Redução Variável dos Ditongos Nasais Átonos. In: BISOL, L; BRESCANCINI, C. (Org.). Fonologia e variação: recortes do português brasileiro. Porto Alegre: EDIPUCRS, 2002.

BISOL, L. Ditongos derivados: um adendo. In: LEE, Seung Hwa (Org.). As vogais além de Belo Horizonte. Minas Gerais, FALE-UFMG, 2012. p. 57-65.

BISOL, L. Fonologia da nasalização. In: ABAURRE, M. B. (Org.). Gramática do português culto falado no Brasil. VII - A Construção Fonológica da Palavra. São Paulo: Contexto, 2013. p. 113-140.

BOPP DA SILVA, Taís. A redução da nasalidade em ditongos de sílaba átona em final devocábulo entre falantes bilíngues e monolíngues do Rio Grande do Sul. Dissertação (Mestrado) - Universidade Federal do Rio Grande do Sul, Porto Alegre, 2005.

BOPP DA SILVA, Taís; SCHWINDT, Luiz Carlos. Panorama da redução da nasalidade em ditongos átonos finais no português do sul do Brasil. In: BISOL, Leda; COLLISCHONN, Gisela (Org.). Português do sul do Brasil: variação fonológica. Porto Alegre: EDIPUCRS, 2009, p. 13-33.

CÂMARA JR, J. M. (1970). Estrutura da língua portuguesa. 42. ed. Petrópolis: Vozes. 2009.

DEMASI, Rita de Cássia Benevides. A ditongação nasal no Português Brasileiro. Dissertação (Mestrado) - Faculdade de Filosofia, Letras e Ciências Humanas. São Paulo: Universidade de São Paulo, 2009.
FREITAG, Raquel Meister Ko. (Re)Discutindo sexo/gênero na sociolinguística. In: FREITAG, Raquel Meister Ko; SEVERO, Cristine Gorski (Org.). Mulheres, linguagem e poder - Estudos de gênero na sociolinguística brasileira. São Paulo: Blucher, 2015.

GOMES, Christina Abreu; MESQUITA, Cássia; FAGUNDES, Taís da Silva. Revisitando a variação entre ditongos nasais finais átonos e vogais orais na comunidade de fala do Rio de Janeiro. Revista Diacrítica, Braga. v. 27, n. 1, 2013.

HOSMER, David W.; LEMESHOW, Stanley. Applied logistic regression. 2. ed. New York: Wiley, 2001.

JOHNSON, Daniel Ezra. Getting off the GoldVarb standard: introducing Rbrul for mixedeffects variable rule analysis. Language and Linguistics Compass, v. 3, n. 1, p. 359-383, 2008.

LABOV, W. (1972). Padrões sociolinguísticos. São Paulo: Parábola, 2008.

LABOV, William. Principles of linguistic change. Vol. 2: Social factors. Oxford: Blackwell, 2001.

OLIVEIRA, Alan Jardel de. "Comendo o final das palavras": análise variacionista da haplologia, elisão e apócope em Itaúna/MG. Tese (Doutorado) - Faculdade de Letras. Universidade Federal de Minas Gerais, Belo Horizonte, 2012.

OLIVEIRA, Alan Jardel. Análise quantitativa no estudo da variação linguística: noções de estatística e análise comparativa entre Varbrul e SPSS. Revista de Estudos da Linguagem, v. 17, p. 93-119, 2009.

SCHERRE, Maria Marta Pereira; YACOVENCO, Lilian Coutinho. A variação linguística e o papel dos fatores sociais: o gênero do falante em foco. Revista da ABRALIN, v. eletrônico, n. esp., p. 121-146, 1르 parte 2011.

WEINREICH, Weinreich; LABOV, William; HERZOG, Marvin. (1968). Fundamentos empíricos para uma teoria da mudança linguística. São Paulo: Parábola Editorial, 2006.

Recebido em 27/08/2016

Aceito em 14/01/2017. 